\title{
IMAGINARIOS DE ESPACIO Y DE SUJETO: JAPONERÍAS EN LA NARRATIVA ARGENTINA, CHILENA Y MEXICANA RECIENTE ${ }^{1}$
}

\section{IMAGINARY OF SPACE AND SUBJECT: “JAPONAISERIES" IN CHILEAN, ARGENTINE AND MEXICAN RECENT NARRATIVE}

\author{
Macarena Areco \\ Pontificia Universidad Católica de Chile \\ mareco@uc.cl
}

\section{Resumen:}

La idea de este trabajo surge a propósito de la recurrencia de imágenes de Japón -y secundariamente de China- en la narrativa latinoamericana reciente. A partir de ella me propongo considerar algunos relatos chilenos, argentinos y mexicanos en que estas aparecen, con el fin de determinar los modos de uso y la posible funcionalidad de lo que he llamado "japonerías" (que incluye las "chinerías"). Para ello comienzo refiriendo algunas de las dimensiones posibles de la proliferación de estas representaciones en el Modernismo; luego analizo desde esta perspectiva seis relatos recientes -Wasabi de Alan Pauls, Bosque quemado de Roberto Brodsky, Bonsái y La vida privada de los árboles de Alejandro Zambra, "Bonsái” de Guadalupe Nettel y El jardín de la señora Murakami de Mario Bellatin-; y finalmente intento, a partir del análisis, fijar algunas posibles significaciones de estas imaginerías para el presente.

Palabras clave: imaginario social, espacio, sujeto, narrativa argentina, chilena y mexicana reciente, japonerías

\begin{abstract}
:
The idea of this paper emerges from the recurrence of images of Japan -and secondarily of China- in recent Latin American narrative. From this, I propose to consider some Chilean, Argentine and Mexican stories in which they appear, in order to determine the modes of use and the possible functionality of what I have called "japonerías" (which includes "chinoiserie"). To do this, I begin by talking about some of the possible dimensions of the proliferation of these representations in Latin American Modernism; then I analyze, from this perspective, six recent stories -Wasabi by Alan Pauls, Bosque quemado by Roberto Brodsky, Bonsái and La vida privada de los árboles by Alejandro Zambra, "Bonsái" by Guadalupe Nettel and El jardín de la señora Murakami by Mario Bellatin-; and finally, I attempt, from the analysis, to set some possible meanings of these imageries for the present.
\end{abstract}

Keywords: Social Imaginary, Spaces, Subjectivity, Chilean, Argentinian and Mexican Recent Narratives, "japonaiseries"

Recibido: 15/10/2016

Aceptado: 23/11/2016

\footnotetext{
${ }^{1}$ Este artículo se desarrolló en el marco del Proyecto Fondecyt Regular No 1130489, titulado "Imaginarios de espacio y de sujeto en la narrativa de dos mil: Chile, Argentina y México".
} 
En el Modernismo el poeta debe equilibrar numerosas contradicciones: la profesionalización con el ejercicio de labores alimentarias; la autonomía con los requerimientos del mercado; la exigencia de una literatura "pura" (en reemplazo de las bellas letras) con una práctica periodística, especialmente de la crónica, cuyo "no estilo" la constituye por oposición ${ }^{2}$. En este mundo desmiracularizado ${ }^{3}$ que le asigna al poeta el "sitio donde duermen los perros", donde "vive como un mendigo exiliado en su casa" (Gutiérrez Girardot 42) ${ }^{4}$ o un jardín donde debe tocar una cantinela hasta que es olvidado y muere congelado ("El rey burgués" de Darío), ni la sobrevivencia ni la escritura están para él garantizadas. Sin considerar este escenario, la constante mención a chinerías y japonerías en las obras modernistas suele ser interpretada por la crítica como "rebeldía frente a la chatura local" (Jiménez) o simplemente como evasión.

Creo que es posible agregar que, frente a la creciente intemperie que cerca al escritor en el capitalismo tardío, las imaginerías orientales operan, aunque desde el extremo opuesto, de un modo similar a las figuraciones sobre el interior, representado como un espacio de refugio y de protección ${ }^{5}$. Los dos versos centrales del soneto de Darío "De invierno" permiten pensar en esta relación, pues si bien el inicio del poema hace referencia al interior que protege a la mujer admirada -"En invernales horas, mirad a Carolina. / Medio apelotonada, descansa en el sillón, / envuelta con su abrigo de marta cibelina /y no lejos del fuego que brilla en el salón" (288)-; el centro -el del poema y el del salón- lo ocupan las chinerías y japonerías -"no lejos de las jarras de porcelana china/ que en medio oculta un biombo de seda del Japón" (288)-, mientras que el final alude a la intemperie de la que el hablante logra, gracias a estos artilugios, protegerse -"y en tanto cae la nieve del cielo de París" (288).

Pienso que es posible ubicar así el interior y las japonerías como el pliegue y el contrapliegue que resultan de la situación del poeta en la modernización. Opuesto a la cercanía y centralidad del interior, Japón (y China) aparece en el imaginario geopolítico

\footnotetext{
2 Según plantea Julio Ramos en Desencuentros de la modernidad en América Latina, "el 'estilo' es precisamente el dispositivo especificador de lo literario en la época, frecuentemente en oposición a los lenguajes desestilizados, mecánicos, de la modernización (Darío: "el repórter no puede tener eso que se llama sencillamente estilo)" (198).

${ }^{3}$ El término pertenece, según Gutiérrez Girardot, a Max Weber, a quien "se debe la precisión del concepto de 'secularización', al que "concibió sumariamente en la conocida fórmula de la 'desmiraculización del mundo'. Esta fórmula equivale a la de 'las ruinas de las destrozadas creencias y supersticiones vestustas' de Valera" (19).

${ }^{4}$ La cita es de un ensayo de Hugo Von Hofmannsthal de 1907, "El poeta y este tiempo" (citado en Gutiérrez Girardot 42).

${ }^{5}$ Ver al artículo de Matías Ayala "El interior en el Modernismo".
} 
occidental, que presupone que en Europa se ubica el centro, como un borde exterior extremo -el "lejano oriente"- que, no obstante, comparte, los atributos protectores del interior. Únicamente si es considerado de este modo, sus biombos y porcelanas pueden representar un refugio para el poeta amenazado. No por lejano Japón deja de ser civilizado, sino que es más bien todo lo contrario: se trata de una civilización alternativa, que es incluso superior en algunos aspectos a la occidental, por ejemplo en lo que se refiere a la relación con la naturaleza, que se imagina caracterizada por la armonía y el control, en lugar de la explotación y la destrucción como los modos propiamente occidentales. Según Renato Ortiz esta ideología plantea la existencia de un:

amor ecológico que se asociaría a la idea de orden social... un vínculo ontológico que relaciona el hombre y la naturaleza... los japoneses tendrían la innata capacidad de interactuar con ella de un modo absolutamente complementario. Al contrario del hombre 'occidental' cuyo propósito sería conquistarla, someterla a su voluntad, preferiría preservarla. (44)

Volviendo a esta suerte de somera introducción histórico-literaria, avanzado el siglo XX, con el agotamiento del Modernismo, este territorio lejano pero civilizado, imaginado como refugio y alternativa, se va borrando. Surge, en cambio, en el periodo de auge de la literatura latinoamericana, un Japón cercano, ya no como espacio exterior ideal sino como un ámbito interior degradado, incluso contaminado. Se trata ahora de japoneses latinoamericanos -el leproso Fushía de La casa verde de Mario Vargas Llosa- o la japonesita de El lugar sin límites de José Donoso-, que se encuentran al margen de los imaginarios éticos y estéticos, protectores y civilizados, de la nación.

Pero si avanzamos algunos años, en el fin de siglo y en el inicio del nuevo, el Japón lejano reaparece en numerosos relatos de autores latinoamericanos, bajo diversas modalidades, ya sea como mera nominación (Wasabi de Alan Pauls) o como homenaje (Memorias de mis putas tristes de García Márquez); ya sea como episodio breve pero relevante (Bosque quemado de Roberto Brodsky), como elemento otorgador de significado para la trama (Bonsái de Alejandro Zambra) o como escenario absoluto y, en este sentido, interiorizado por la diégesis (El jardín de la señora Murakami de Mario Bellatin y "Bonsai" de Guadalupe Nettel). La constatación de esta proliferación de japonerías es la que motiva a interpretarla.

Quizás sea necesario advertir que con este trabajo no me propongo investigar un Japón realista o mimético, ni menos descubrir qué del Japón verdadero hay en las obras estudiadas, sino que mi intención es analizar el territorio imaginado por los autores para 
tratar de responder de qué sirve Japón a estas obras, cuál es la necesidad, el deseo que Japón permite vislumbrar. Las imaginerías japonesas, su modo de uso y su posible funcionalidad son, entonces, la materia de este trabajo, no su realidad. Dado que se trata de un territorio inventado, me he permitido emplear el término japonería no solo respecto a figuras referenciadas en los relatos como japonesas, que, en cualquier caso, son las que priman, sino que ocasionalmente para otras designadas como chinas e incluso a alguna indeterminada, como se verá más adelante ${ }^{6}$.

\section{Wasabi: Japón como un signo vacío}

La novela de Alan Pauls, publicada en 1994, la primera de la serie que he elegido, cuyo título repite el del verde condimento japonés, relata lo que le acontece a un argentino sin nombre y a su pareja Tellas, a partir de su estadía en una residencia para escritores en Saint-Nazaire, Francia. La situación podría pasar por idílica de no ser porque, estando en aquella ciudad, al personaje le brota un quiste con forma de espolón o de perchero en la base de la nuca, el que intenta sanar con una pomada homeopática, que no produce ningún efecto, pero que sí tiene propiedades afrodisiacas. A este medicamento que no cura le llaman, al igual que la novela, wasabi. Además, el escritor sufre episodios de narcolepsia que duran siete minutos exactos, de los que no recuerda nada, por los que los define como amnesia (21). Pasado un tiempo, y aburrido en SaintNazaire, el personaje viaja a París, donde es asaltado en el metro por unos jóvenes irlandeses y sufre un colapso que dura varios días, en el que se transforma en un mendigo que deambula por las calles de la capital francesa. De esta situación lo salva un dramaturgo chino a quien ha conocido en Saint-Nazaire y al que antes ha definido como alguien despreciable. El colapso, descrito como un infierno en que todas las cosas desaparecen y los espacios, la ciudad y las distancias se volatilizan en el aire (82), se condensa en algo que se considera como lo peor, "la falta absoluta del estilo" (83). Entonces, un recuerdo, llamado también reminiscencia y revelación, se le aparece como un esperanzador "rayo de sol" (84): "Un banco de madera a orillas del estuario, cerca del muelle abandonado, donde Tellas y yo, ateridos, nos habíamos demorado una tarde de

\footnotetext{
${ }^{6}$ Teóricamente este ensayo se sustenta en la conceptualización del imaginario social que desarrolla Cornelius Castoriadis, la cual es complementada con las ideas de autores más recientes. En términos generales, el imaginario social se entiende como "figuras/formas/imágenes" (Castoriadis 1975) o "ideasimágenes" (Baczko 2005) que articulan visiones sociales propias de distintos momentos históricos y que "fabrican" realidad (Ludmer 2010). A partir de este enfoque en distintos trabajos he estudiado algunas figuraciones imaginarias recurrentes en la literatura latinoamericana reciente, referidas a subjetividades y a espacios, entre ellas el imbunche y el acuario, y, en este caso en particular, lo que he llamado "japonerías".
} 
tormenta. No había nada en esta reminiscencia que me confortara... pero lo que brillaba era la existencia el recuerdo, no su contenido" (83). Toda la trama parece bastante perdida y desconectada, desde la narcolepsia gratuita hasta la conversión en mendigo, culminando en esa especie de deus ex machina que son el dramaturgo chino salvador y la reminiscencia. La historia y el recuerdo final aparecen sin contenido y el estilo parece ser lo único en última instancia valorado. El desenlace sigue en esta línea: el narrador se reencuentra con Tellas, quien está embarazada; ambos deciden que al niño le pondrán Wasabi.

En esta primera aparición de una japonería en el corpus que he elegido para este trabajo, ésta es sólo un sustantivo exótico que llena una suerte de vacío: el título de un libro, el apodo de una pomada y el futuro nombre de un niño; nada más hay de Japón en la novela, salvo la presencia del dramaturgo chino, que pertenece al mismo campo imaginario. Un escritor amnésico, un remedio que no cura y la espera de un hijo -¿una esperanza? El Japón de Pauls coincide con el de Barthes; es un significante hueco con un valor fundamentalmente estético que se contrapone a lo vulgar:

El signo japonés está vacío: su significado huye, no hay dios ni verdad, ni moral en el fondo de estos significantes que reinan sin contrapartida. Y sobre todo, la calidad superior de este signo, la nobleza de su afirmación y la gracia erótica con que se dibuja, están situadas por todas partes, sobre los objetos y sobre las conductas más banales, las que de ordinario remitimos a la insignificancia o la vulgaridad. (3)

Poco de Japón hay en esta novela inicial que más bien parece dar cuenta del deseo de una posibilidad estética, de un estilo, vacíos de contenido.

\section{Bosque quemado: el paliativo después del naufragio}

La novela de Roberto Brodsky Bosque quemado, publicada en 2008, también tiene entre sus núcleos temáticos principales la amnesia, pero no la del escritor, sino la del padre de éste, Moisés, un cardiólogo chileno de origen judío que sufre los rigores del exilio y una separación matrimonial, y que al final será consumido por el alzheimer. Una sola pausa de optimismo se describe en esta biografía que relata el derrumbe de las esperanzas personales y políticas en el fin de siglo: a fines de los noventa el personaje busca una segunda oportunidad sentimental con una actriz judía de teatro Noh, para lo cual invierte grandes esfuerzos económicos y anímicos en busca de una vida privada perfecta. Adquiere así una costosa propiedad en las alturas de la ciudad, la que decora al estilo japonés, con "pisos insonorizados y biombos de papel de mantequilla", que exige 
de él comportamientos y rituales sofisticados: "complicadas posturas corporales ante las lonjas de sushi" (17) en la cena y charlas "con diaporama incluido sobre los ritos del Noh, el haikú y la poesía del silencio" (18). En este proyecto de vida lo japonés aparece en una visión idealizada, una suerte de sanidad vital, que parece tener la facultad de asegurar, después del fracaso y del exilio, una segunda oportunidad a los náufragos de la historia, quienes han vagado por un desierto íngrimo, y han sido "marcados para siempre por la extrañeza y el desajuste, por la destrucción ajena y la mutilación de los deseos propios, por la volatilidad de las causas y la duración irreductible de los efectos, por la amenaza de un nuevo giro catastrófico de las cosas que nos mantenía sin pegar pestaña como si vigiláramos la intemperie" (100). Algo así como la idea que Nietzsche se hace del budismo como religión "tardía, para el acabamiento y el cansancio de las civilizaciones" (47), "para hombres tardíos, para razas que se han vuelto bondadosas, mansas, superespirituales, que con demasiada facilidad sienten dolor" (47). O una posibilidad después del apocalipsis.

A pesar del enorme "esfuerzo por un buen desempeño", el proyecto japonés fracasa, sus posibilidades curativas no funcionan, y el padre termina pidiendo asilo al hijo, después de lo cual enferma de alzheimer. Relacionado con este último, una segunda imagen de Japón se presenta en la novela: el narrador ve en una exposición las fotografías que el artista japonés Tatsumi Orimoto se ha tomado junto a su madre, quien sufre de este mal, rodeados de marraquetas y hallulas. Sobre ello se explica: "la disposición de objetos primarios y de necesidad básica como los zapatos o un simple pedazo de pan eran capaces de aliviar la perturbación mental de los enfermos de Alzheimer, o al menos disminuir sus efectos, creando un entorno de afectividad que por lo general les estaba negado" (87). Aunque en una perspectiva más actual, concreta y material, vuelven a aparecer imágenes vinculadas a Japón como un paliativo frente a una situación terminal, que, sin embargo, no da resultado. Las japonerías -ya sea en su versión idílica o en la material- son aquí algo así como una esperanza final, un orden después del caos, un amor después del amor, un arraigo después del exilio, un último estertor de moribundo luego de que las esperanzas sociales, políticas y personales han muerto; un tratamiento especial para aquellos que han sufrido la condena de la historia, pero que, como en Wasabi, no tiene capacidad de cura. 


\section{Bonsái y La vida privada de los árboles: japonerías metaliterarias}

A diferencia de la novela de Pauls, en que el título en japonés es un significante vacío, en la primera novela de Alejandro Zambra la palabra bonsái que la nombra es llenada con un contenido metaliterario significativo, enlazado con una visión acerca de la naturaleza. Inmediatamente después del título, el epígrafe de Kawabata, vuelve a marcar la importancia de Japón y, al hacer referencia a un personaje literario, da un primer indicio de su vínculo con la metaficcionalidad: "Pasaban los años, y la única persona que no cambiaba era la joven de su libro". Y si luego consideramos la estructura y la extensión del relato también podemos percibir esta velada presencia del país de oriente, en tanto el minimalismo es una de sus características en el imaginario occidental. ${ }^{7}$ Así, Bonsái es una novela muy breve -94 páginas muy espaciadas-, con una trama elemental, que ya se sintetiza en la primera línea -“Al final ella muere y él se queda solo” (13)- y que desarrollada no requiere de muchas más, pero en la que destaca la escritura de una novela por parte del personaje -llamado conjeturalmente Julio- en paralelo a la creación de un bonsái. La producción del árbol en miniatura refiere explícitamente a la escritura: “Cuidar un bonsái es como escribir, piensa Julio. Escribir es como cuidar un bonsái” (87). A partir de este símil, la novela parece enunciar una suerte de poética que liga naturaleza y escritura: "Un bonsái es una réplica artística de un árbol en miniatura. Consta de dos elementos: el árbol vivo y el recipiente. Los dos elementos tienen que estar en armonía y la selección de la maceta apropiada para un árbol es casi una forma de arte por sí misma" (85-86). La descripción, que enfatiza la importancia de poner límites, parece ser una reflexión acerca de la necesidad del control en el arte. Como se dice en el segundo epígrafe, de Gonzalo Millán, el dolor, que podría ser la materia de la escritura, "se talla y se detalla". Una naturaleza contenida en un marco, un sentimiento tallado a través de la escritura: construir un bonsái es artificializar la naturaleza, escribir un libro es detallar y controlar los sentimientos de manera que hagan posible una obra de arte; solo al costo de la mutilación es posible crear un bonsái y escribir un libro. La posibilidad del arte se basa en la ascesis.

En La vida privada de los árboles, la segunda novela de Zambra, la metatexualidad asociada al árbol japonés también es central. En ella no sólo aparece un

\footnotetext{
${ }^{7}$ Un ejemplo en la siguiente descripción de Barthes: "En el mercado flotante de Bangkok, cada comerciante se mantiene en una pequeña piragua inmóvil; vende muy menudas cantidades de comida... Desde él mismo hasta la mercancía, pasando por su esquife, todo es pequeño. La comida occidental, acumulada, dignificada, hinchada hasta lo majestuoso, ligada a cualquier operación de prestigio, se orienta siempre hacia lo grueso, lo grande, lo abundante, lo copioso; la oriental sigue el movimiento inverso, se expande hacia lo infinitesimal: el futuro del pepino no es su amontonamiento o su condensación, sino su división" (23).
} 
resumen de Bonsái -"Si alguien le pidiera resumir su libro, probablemente respondería que se trata de 'un hombre joven que se dedica a cuidar un bonsái... un hombre encerrado con su bonsái, cuidándolo, conmovido por la posibilidad de una obra de arte verdadera" (28-9)-, sino que también se dice que su protagonista, el escritor Julián, es el autor del relato:

Acaba de terminar un libro muy breve, que sin embargo le tomó varios años escribir. En un principio se dedicó a acumular materiales: llegó a juntar casi trescientas páginas, pero luego fue descartando pasajes, como si en lugar de sumar historias quisiera restarlas o borrarlas. El resultado es pobre: una escuálida resma de siete hojas que él se empeña en considerar una novela. (27-8).

Como se percibe aquí, el bonsái que metaforiza el control que hace posible la escritura vuelve a aparecer en este segundo relato. Pero también se da la imagen contraria, en la historia que Julián le cuenta a su hijastra Daniela sobre Okoto (y que repite la de su esposa Verónica), una pintora que no puede ejercer su arte debido a que los brazos le han crecido demasiado, por lo que se dedica a recoger hojas en el parque. La imposibilidad de la pintura se debe a la confusión del artista con la naturaleza. Ya no la naturaleza como artificio del bonsái, sino que lo contrario, la mujer como naturaleza, representación que, como sabemos, se repite de manera recurrente en el arte y la literatura, desde la Ofelia de Shakespeare hasta las protagonistas de María Luisa Bombal. $^{8}$ Los relatos mexicanos que analizaré a continuación trabajan estos vínculos entre naturaleza, identidad y capacidad de agencia.

\section{“Bonsái” y El jardín de la señora Murakami: posibilidades e imposibilidades de la identidad y la agencia}

Dos ficciones mexicanas recientes representan un oriente interiorizado, es decir uno que engloba la totalidad de la diégesis, ya no dentro de un marco latinoamericano. Se trata del cuento de Guadalupe Nettel también titulado "Bonsái” (2007, 2008) y de la nouvelle El jardín de la señora Murakami (2000) de Mario Bellatin. En ambos la japonería es preponderantemente natural, pues tiene como centro el parque, el invernadero y el jardín, pero las imágenes de que dan cuenta son inversas.

En "Bonsái" se narra la historia de un personaje que los domingos visita un parque público -el jardín de Aoyoma- como una manera de escapar a los requerimientos

\footnotetext{
${ }^{8}$ En un artículo que se publicará en Hispamérica -"Ellas hablan con nadie en el jardín": naturaleza y subalternidad en relatos de María Luisa Bombal y Alejandro Zambra”, ahondo en esta situación.
} 
de su mujer de hacer reparaciones domésticas. Al comienzo no son las plantas lo importante para él, pero esto cambia cuando comienza a visitar el invernadero, donde conversa con el anciano jardinero, el señor Murakami. Entonces se va interesando progresivamente por las diversas especies hasta que se identifica con una de ellas, los cactus: "Si yo hubiera nacido planta -reconocí para mis adentros- no habría sino podido pertenecer a ese género" (259). Descubre entonces, al modo de un escritor naturalista, las incompatibilidades de temperamentos con su esposa -ella es una enredadera- lo que lleva a que finalmente terminen separándose. El bonsái que da título al cuento sólo aparece una vez y es una reproducción exacta del jardín de Aoyama en miniatura. La creación le produce "un malestar casi físico" (262) al protagonista y es calificada por el jardinero de “aberrante". Este le explica: "los bonsáis son solo eso, bonsáis, árboles que traicionan su verdadera naturaleza" (263). El personaje reconoce esa autotraición en su esposa, cuando ella vuelve del salón de belleza "Entonces me di cuenta: lo que estaba viendo frente a mí era una perfecto bonsái. El bonsái de una enredadera" (264).

Las japonerías como productoras de subjetividad e individuación tienen efectos emancipadores:

Fue como una liberación. En ese momento dejé de preocuparme por cosas que antes me pesaban y me causaban angustia... También por esas fechas dejé de propinar sonrisas hipócritas... No era falta de amabilidad, sino simple coherencia con mi naturaleza. Y, al contrario de lo que se podía esperar, la gente no lo tomó a mal. Es más, los compañeros de oficina comentaban que últimamente me veía 'en buena forma', incluso 'más natural'. (260)

En cambio, los bonsái representan una identidad artificial que impide ser feliz: "Yo amaba a Midori, pero dejarme invadir era actuar en contra de mi naturaleza. También pensé en lo traicionada y triste que sería una enredadera incapaz de reproducirse" (263). Si bien el desenlace nostálgico relativiza las asociaciones éticas "Pensé en mi vida con una enredadera y en lo rápido que había transcurrido. Recordé sobre todo la longevidad de los cactus: ochenta años o más en una tierra seca y cobriza" (266)- ello no invalida las relaciones que se proponen entre jardín japonés, bonsái y subjetivación. Reconocer una cierta identidad, que, dentro de imaginario "natualista" de este relato, corresponde a una esencia, a través de la identificación con un determinado tipo de planta, es un proceso liberador para el sujeto, que le permite comportarse de acuerdo a lo que, desde la visión del texto, realmente es. 
En El jardín de la señora Murakami ocurre todo lo contrario, pues lo que en ella se relata es el trayecto que realiza Izu hasta convertirse en la señora Murakami, que va desde la individuación y la capacidad de agencia a la sujeción, la dependencia y la pobreza ${ }^{9}$. Cuando niña Izu fue una persona independiente, creativa e inteligente "' $[\mathrm{d}]$ esde la infancia había querido ser parte activa de la vida pública. Siempre había intentado demostrar que estaba preparada para enfrentarla" (165). ${ }^{10}$ En su juventud tuvo dos pretendientes que por distintos motivos no han llegado a ser sus maridos, lo que ha incidido en que opte por dedicarse por completo a sus estudios de teoría del arte en la universidad, no como un paliativo sino por vocación: "no le importaba haber dejado de lado los asuntos sentimentales si esa decisión le permitía dedicarse a ser una crítica destacada" (167), dice el narrador, quien también relata que los padres convirtieron "el salón destinado a la ceremonia del té en un estudio en el que se pudiera dedicar con disciplina a su tarea intelectual" (163), en una imagen que da cuenta de la modernización efectuada y de las posibilidades de autonomía que se le abren a la joven, quien dispone de un "cuarto propio". El escritorio da a un jardín "que si bien era algo refinado no se comparaba con el que Izu disfrutaría después de su boda" (157), por el cual pasaba un riachuelo en pendiente, que no le permitió cultivar peces, detalle importante para el análisis, como se verá más adelante.

Debido a sus estudios la joven conoce al señor Murakami, un coleccionista de arte viudo, con quien termina casándose, debido a una complicada serie de secuencias que mezcla la culpa por haber publicado un artículo criticando la colección, la traición a los profesores progresistas y el retiro de la universidad. El acercamiento del señor Murakami se presenta desde el inicio con signos ominosos; el primer regalo que le envía es "un ramo de orquídeas negras" (153). Y más adelante, cuando pide su mano, exige que la familia le aplique el formotón asai, es decir, que la repudie, lo que la madre termina aceptando a causa de un chantaje:

El señor Murakami exigía que su futura esposa renunciara a la dote para convertirse, de ese modo, en un marido de la vieja estirpe. Recibiría una

\footnotetext{
9 Por agencia quiero decir, lo que Jonathan Culler ha explicado como "la cuestión de hasta qué punto podemos ser sujetos responsables de nuestras acciones o nuestras acciones nos son impuestas por fuerzas que no controlamos" (60).

${ }^{10}$ También en la infancia participa de juegos que sólo estaban permitidos para los varones e inventa una terapia para otros niños: "durante la hora de recreo instalaba en el suelo una suerte de consultorio psicológico donde atendía a los niños que tuvieran problemas con sus estudios, con sus padres, o incluso con asuntos de carácter sentimental. Nadie sabía por qué pero los niños aguardaban pacientemente su turno. Izu los escuchaba primero en silencio. Dejaba que expresaran libremente lo que querían decir. Luego abría un libro de haikus... del cual citaba uno o varios poemas dependiendo de la importancia del asunto" (1789).
} 
mujer sin nombre, sin privilegios y sin dinero. La madre le suplicó que no pidiera la mano de su hija. Pero el señor Murakami le dijo que poseía pruebas de la presencia de Izu en el hotel donde se realizaron las citas clandestinas. Tenía también unas fotos... en las que aparecía Izu semidesnuda. (197)

Aunque la madre intenta buscar salidas, Izu ha decidido que quiere casarse: "Había llegado a esa conclusión luego de mirar, una y otra vez, el reflejo de la solitaria flor amarilla que ciertas noches aparecía en el centro de su pequeño jardín" (198). El jardín, imaginado en el relato de Nettel como un factor de subjetivación, aparece aquí ligado al proceso de pérdida de agencia de la protagonista, lo que se refuerza con el hecho de que, a cambio del pacto matrimonial que tanto la perjudica, solo pide un jardín tradicional, con senderos acuáticos y un lago con carpas doradas.

Los peces son importantes para comprender el sentido del texto. Como ya dije, en el primer jardín de la estudiante Izu no es posible mantener peces, pero en este segundo, se dice que la señora Murakami contempla durante horas "los reflejos de las escamas y las colas" (151). Por otra parte, cuando la joven deja la casa de sus padres cena con el señor Murakami en un restaurante:

donde ofrecían la carne recién cortada de un pez que regresaba descarnado pero vivo a una pequeña pecera que luego ponían sobre la mesa. La comida debía durar el tiempo exacto que tardaba el pobre animal en dejar de nadar y morir. También era posible, cuando servían el té, apreciar el proceso completo de florecimiento de una rama de cerezo adaptada especialmente para que eso sucediera así. (198)

Esta ceremonia tradicional parece alegorizar la destrucción de la personalidad de Izu. El pez dentro de la pecera -imagen recurrente en la narrativa actual de la falta de agencia de los personajes ${ }^{11}$ - es una representación de la propia señora Murakami. Para hacer más perfecta la ironía, mientras ella defiende entusiastamente esos artilugios, el marido los desprecia.

La novela termina de manera circular, con la palara otsomuru que, según se indica en una nota, "refiere al final que es en realidad un comienzo" (199), así como ha empezado cuando la historia termina: después de la muerte del marido, en cuya agonía ha revelado que tuvo por amante a la sirvienta de Izu, ésta, que con la viudez enfrenta la pobreza, ordena la demolición de su jardín. A partir de esta destrucción adquieren sentido diversos indicios poco comprensibles en una primera lectura: la complejidad de la

\footnotetext{
${ }^{11}$ En un artículo todavía inédito "Imaginario espacial en la narrativa chilena reciente: el acuario como representación de la intimidad en relatos de Contreras, Zambra y Bolaño" he analizado esto.
} 
disposición temporal que va entrecruzando fragmentos de la diégesis y finalmente se cierra en un círculo; la elisión o la descripción fugaz de los núcleos temáticos (por ejemplo del matrimonio de Izu y de su vida de casada); las notas a pie de página que, como la primera, a veces solo remiten a una nota futura o que en ocasiones explican cuestiones ultra conocidas, como qué es un kimono o un futón; las detalladas descripciones de la ropa de Izu; el empleo de nombres japoneses asociados en occidente con escritores o marcas famosas, como Murakami, Kenzó, Mitsubishi; la descripción de rituales absurdos como la cacería de orugas en los años bisiestos. Pero lo más desconcertante es la información, bastante avanzado el relato, de que el espacio en que trascurre la historia, pródigo en japonerías -bambúes, tatamis, ceremonia del té, kabuki...-, no es Japón, país que ha sido destruido: "En esa época el padre del señor Murakami aún mantenía relaciones con el Japón... En aquel entonces algunos miembros de la familia hacían largos viajes a aquellas islas. Pero Shikibu no las había vuelto a oír nombrar desde que se difundió la terrible noticia de que una bomba lo había convertido en un país en ruinas" (172). Parece que el narrador se estuviera riendo del lector. En la repetición del gesto vanguardista de Magritte -Esto no es Japón- y en la destrucción del jardín de la señora Murakami y del propio país oriental creo que Bellatin intenta burlar los imaginarios orientalistas de armonía con la naturaleza, las pastorales modernistas y posmodernistas que se figuran el más allá japonés como la posibilidad de una vida estetizada y protegida. En lugar de eso, difumina el referente imaginario, lo contamina con referencias absurdas e incluso con prácticas bárbaras, lo destruye en un nuevo apocalipsis, se burla e ironiza.

\section{Conclusión}

La recurrencia de imágenes de Japón en la narrativa latinoamericana reciente, en relatos de autores argentinos, chilenos y mexicanos -como Wasabi de Alan Pauls, Bosque quemado de Roberto Brodsky, Bonsái y La vida privada de los árboles de Alejandro Zambra, "Bonsái" de Guadalupe Nettel y El jardín de la señora Murakami de Mario Bellatin- puede interpretarse como un imperativo posapocalíptico, que opera al modo de un bálsamo o un calmante, una vez que lo que Bolaño llamaría "las guerras floridas" (Estrella distante 11) en Latinoamérica han terminado con las esperanzas de cambio y han dejado el continente sembrado de cadáveres. En el olvido de estas expectativas, las japonerías harían posible imaginar un modo de vida individual y familiar más simple y ordenado, en cercanía y armonía con la naturaleza; una tranquilidad que nos permitiría 
trascender el tráfago, las contradicciones, los golpes, el movimiento, el "tempo" rápido, en fin, la intensidad de la vida moderna o posmoderna, de la excitación nerviosa en que nos envuelve el capitalismo avanzado.

Japón como "la posibilidad de una isla" (Houellebecq) después de las esperanzas perdidas, públicas y privadas, o como un sofisticado remedio que promete un nuevo estilo de vida calmo y estético. Pero esta recurrencia también responde a la necesidad de deconstruir ese imperativo, cuestionando su realidad, develando las imposturas de esta estetización y destruyéndola. El Japón que se imagina desde Chile, Argentina o México, parecen decirnos algunas de estas narraciones, es una convención, un espejismo, un simulacro, pues las relaciones de poder y de género siguen siendo inamovibles y de hierro, o quizás lo sean más que antes para un medio cultural que se siente a salvo gracias a una aparente liberalización del arte, como podría querer decir la historia de la señora Murakami y su jardín.

\section{Bibliografía}

Ayala, Matías. "El interior en el Modernismo". Estudios filológicos 41 (2006): 7-18. Impreso.

Barthes, Roland. 1970. El imperio de los signos. Barcelona: Seix Barral, 2007. Impreso.

Baczko, Bronislaw. Los imaginarios sociales. Memorias y esperanzas colectivas. Buenos Aires: Nueva Visión, 2005. Impreso.

Bellatin, Mario. "El jardín de la señora Murakami”. (2000). En Obra reunida. México D.F.: Alfaguara, 2005. Impreso.

Bolaño, Roberto. Estrella distante. Barcelona: Anagrama, 2008. Impreso.

Brodsky, Ricardo. Bosque quemado. Barcelona: Mondadori, 2007. Impreso.

Castoriadis, Cornelius. 1975. La institución imaginaria de la sociedad. Buenos Aires: Tusquets, 2007. Impreso.

Culler, Jonathan. Breve introducción a la teoría literaria. Barcelona: Crítica, 2004. Impreso.

Darío, Rubén. Azul... Cantos de vida y esperanza. Madrid: Cátedra, 2010. Impreso.

Gutiérrez, Girardot, Rafael. El modernismo. Supuestos históricos y culturales. México: Fondo de Cultura Económica, 1983. Impreso.

Jiménez, José Olivio y Carlos Javier Morales. La prosa modernista hispanoamericana. Introducción crítica y antología. Madrid: Alianza, 1998. Impreso.

Ludmer, Josefina. Aquí América Latina: una especulación. Buenos Aires: Eterna cadencia, 2010. Impreso.

Ortiz, Renato. Lo próximo y lo distante. Japón y la modernidad-mundo. Buenos Aires: Interzona, 2003. Impreso.

Pauls, Alan. 1994. Wasabi. Barcelona: Anagrama, 2005. Impreso.

Nietzsche, Friedrich. El Anticristo. Madrid: Alianza, 1996. Impreso.

Nettel, Guadalupe. "Bonsái”. En Bogotá 39. Antología del cuento latinoamericano. Bogotá: Ediciones B, 2007. Impreso. 
Ramos, Julio. Desencuentros de la modernidad en América Latina. Literatura y política en el siglo XIX. Caracas: Fundación Editorial El perro y la rana, 2009. Impreso.

Zambra, Alejandro. Bonsái. Barcelona: Anagrama, 2006. Impreso.

. La vida privada de los árboles. Barcelona: Anagrama, 2007. Impreso. 